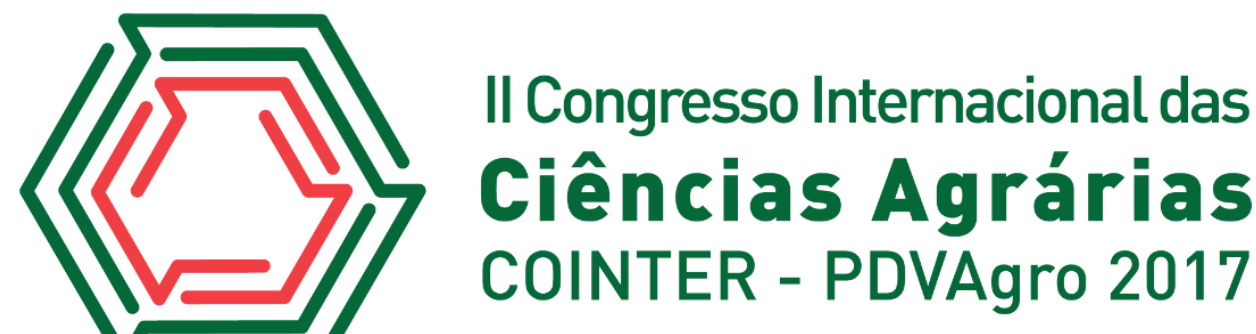

\section{ANÁLISE DO CONTEÚDO RELATIVO DE ÁGUA, CLOROFILAS A, B E TOTAL E CAROTENÓIDES NAS ESPÉCIES BACABA E BACABI COM DEFICIÊNCIA HÍDRICA}

Ana Ecídia de Araújo Brito ${ }^{1}$; Karollyne Renata Souza Silva ${ }^{2}$; Tamires Borges de Oliveira ${ }^{3}$; Antônia Benedita da Silva Bronze ${ }^{4}$; Cândido Ferreira de Oliveira Neto ${ }^{5}$

\section{Introdução}

A Família Arecaceae, é de suma importância para as populações tradicionais e comunidades indígenas da região Amazônica (MIRANDA; RABELO, 2006), é constituída por um grande número de espécies com potencial para a produção de frutos e palmito. A diminuição na disponibilidade hídrica causa o fechamento dos estômatos devido à redução no potencial hídrico foliar, o qual proporciona perda de turgescência, promovendo declínio na condutância estomática (FLEXAS; MEDRANO, 2002; FLEXAS et al., 2004).

As plantas defendem-se continuamente contra situações de estresse sejam eles bióticos ou abióticos. Os dados causados pelo estresse hídrico são minimizados pelo sistema enzimático antioxidante, bem como por outros processos fisiológicos e bioquímicos que induzem e, ou, aceleram a produção ou acumulo de solutos compatíveis (MOLINARI et al., 2007).

Assim, o trabalho teve o objetivo de ampliar os conhecimentos sobre os mecanismos de respostas da Oenocarpus bacaba Mart. e da Oenocarpus mapora H. Karsten, mediante estudos de características fisiológicas e bioquímicas visando uma melhor compreensão das estratégias desenvolvidas por estas espécies quando submetidas a deficiência hídrica. Tendo como hipótese que a deficiência hídrica afetará negativamente as variáveis estudadas.

\section{Fundamentação Teórica}

A bacabeira apresenta grande potencial econômico, ecológico e alimentar, constituindo-se em uma espécie passível de ser incorporada aos sistemas agroflorestais. É usualmente explorada em seus ambientes naturais, devido os frutos serem comestíveis, sua principal utilização é pela produção de polpa e suco na extração de um óleo comestível, semelhante ao azeite de oliva e o palmito (MENDONÇA e ARAÚJO, 1999; QUEIROZ e BIANCO, 2009).

\footnotetext{
${ }^{1}$ Pós-graduação em Agronomia, Universidade Federal Rural da Amazônia, ecidiabrito@ hotmail.com

${ }^{2}$ Graduação em Agronomia, Universidade Federal Rural da Amazônia, karollyne-silva@ hotmail.com

${ }^{3}$ Pós-graduação em Ciências Florestais, Universidade Federal Rural da Amazônia, tamyborges@yahoo.com.br

${ }^{4}$ Professora doutora, Universidade Federal Rural da Amazônia, antonia.silva@ufra.edu.br

${ }^{5}$ Professor doutor, Universidade Federal Rural da Amazônia, candido.neto@ufra.edu.br
} 
De acordo com Pereira (2006), no desenvolvimento e crescimento de um vegetal, a água se mostra crucial em diversos aspectos, dentre eles destacam-se: envolvimento na fotossíntese como fonte de elétrons para produção de energia, após ativação da clorofila.

Segundo Angelocci, (2002), a deficiência hídrica é uma medida que relacionada ao balanço hídrico que representa a defasagem entre absorção e a transpiração do vegetal; enquanto que o termo estresse hídrico caracteriza uma situação em que a deficiência hídrica é de grau potencialmente danoso à planta.

\section{Metodologia}

O experimento foi conduzido em casa de vegetação pertencente à UFRA - Universidade Federal Rural da Amazônia, Belém, Pará, no período de Fevereiro a Julho de 2015, o delineamento experimental inteiramente casualizado (DIC) em esquema fatorial 2 (espécies) x 2 (status hídricoscontrole e deficiência hídrica) x 4 (tempos 0,15,30 e 35 dias), e cinco repetições, perfazendo 40 unidades experimentais. O conteúdo relativo de água foi mensurado entre 4:00 e 5:00h da manhã em cada coleta do experimento, utilizando-se o método descrito por SLAVICK (1979), com algumas modificações.

A quantificação das clorofilas $a, b$, carotenóides e total utilizando espectrofotômetro Femto (700S), de acordo com a metodologia de LICHTHENTHALER (1987). Todas as coletas para análise bioquímicas foram realizadas aos $0,15,30$, e 35 dias logo após o período de aclimatação, entre 04:30 e 05:30h, o último dia (35) correspondeu a reidratação. Utilizando-se análise de variância (ANOVA) no programa Assistat versão 7.7 beta e, as médias comparadas pelo teste de Scott-Knott ao nível de $5 \%$ de probabilidade.

\section{Resultados e Discussões}

O déficit hídrico (não irrigado) ao longo dos 30 dias do experimento (Figura 1) promoveu uma redução no conteúdo relativo de água (CRA) nas plantas de bacaba, a partir do trigésimo dia chegando a valores próximos a 50\%, enquanto as plantas irrigadas (controle) obtiveram valores entre $89,8 \%$ a $93,8 \%$. O mesmo ocorreu nas plantas de bacabi mantidas sob deficiência hídrica promovendo uma redução no conteúdo relativo de água (CRA) (Figura 1), chegando a valores próximos de $59 \%$.

Quando as mudas de bacaba foram submetidas à re-hidratação os valores de CRA elevaram significativamente, com valores próximos a $84 \%$, se aproximando aos resultados do controle 
(plantas irrigadas) com 89,8\% a 93,8\%. Já para as plantas de bacabi essa re-hidratação não foram suficientes para elevar de maneira significativa o conteúdo relativo de água das plantas.

Essa redução do conteúdo relativo de água nas plantas sob deficiência hídrica ocorreu devido à menor disponibilidade de água no solo, interferindo na formação de um gradiente de concentração e desfavorecendo a absorção de água pela planta. O decréscimo na disponibilidade de água no solo ocasiona queda no potencial hídrico nas folhas das plantas, afetando as trocas de dióxido de carbono e o metabolismo da planta, sendo esta uma forma de defesa das plantas (REIS et al., 2008; ALVES et al., 2012; SILVA et al., 2013).

Figura 1. Conteúdo relativo de água (CRA) em plantas de bacaba e bacabi submetidos à deficiência hídrica e rehidratação.
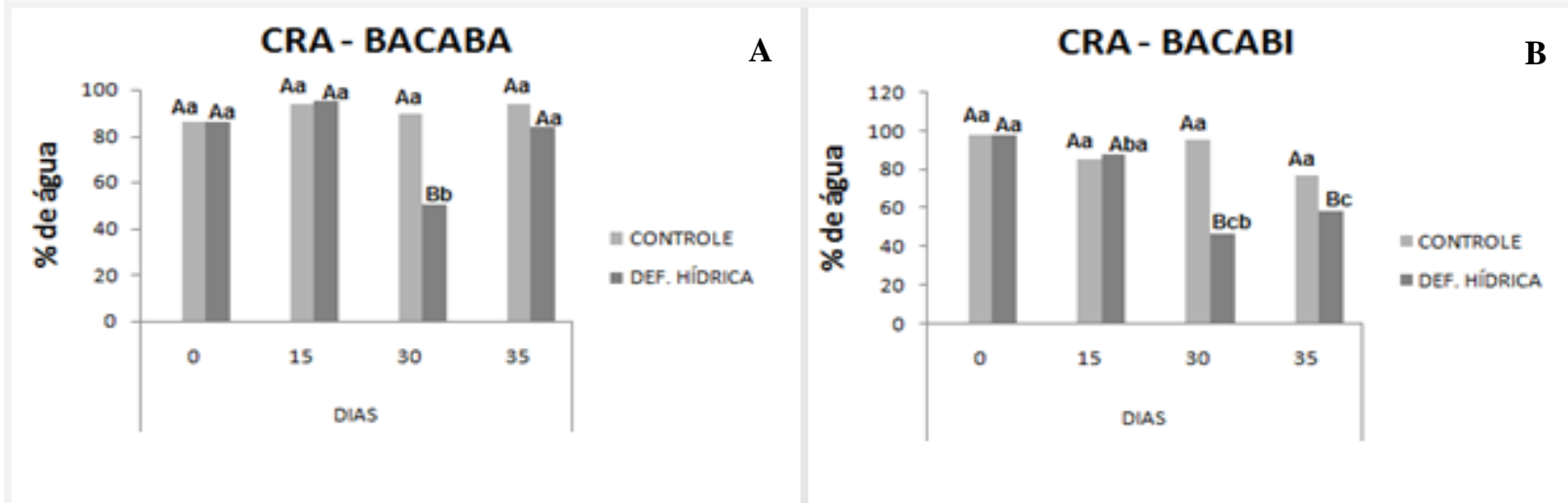

Observou-se um aumento significativo nos teores de clorofila $a, b$ e totais nas folhas de bacaba entre os regimes hídricos e os dias de estresse (Figura 2). Os teores de carotenóides em plantas de Oenocarpus bacaba entre os regimes hídricos e os dias de estresse (Figura 2 D), sendo observada uma redução gradativa ao longo dos dias de tratamento e que os dias de re-hidratação foram suficientes para aumentar os teores de carotenóides em plântulas de bacabeira.

Ocorreu uma aumento nos teores de clorofila $a, b$ e totais nas folhas de bacabi entre os regimes hídricos e os dias de estresse (Figura 3). Os teores de carotenóides em plantas de Oenocarpus mapora entre os regimes hídricos e os dias de estresse (Figura 3D), sendo observado uma redução gradativa ao longo dos dias de tratamento e que os dias de re-hidratação foram suficientes para aumentar os teores de carotenóides em plântulas de bacabi.

Segundo Engel \& Poggiani (1991), a eficiência fotossintética está ligada ao teor de clorofila das plantas, afetando o crescimento e influenciando a adaptabilidade das mesmas aos diversos ambientes. De acordo com Lee (1988), estudos realizados evidenciaram que os teores de clorofila variam muito entre as espécies, assim como entre genótipos de uma mesma espécie, o que 
corrobora com os resultados deste estudo, mostrando que os teores de clorofila $a$, $b$ e totais obtiveram valores diferentes para as plantas de Oenocarpus bacaba Mart e Oenocarpus mapora Karsten, contudo em ambas os maiores teores de clorofila foram ao trigésimo dia, que corresponde pelo o maior nível de estresse.

Figura 2. Teores de Clorofila $a$ (A), $b$ (B), totais (C) e Carotenoides (D) nas plantas de Oenocarpus bacaba submetidas aos tratamentos controle, deficiência hídrica e reidratação.

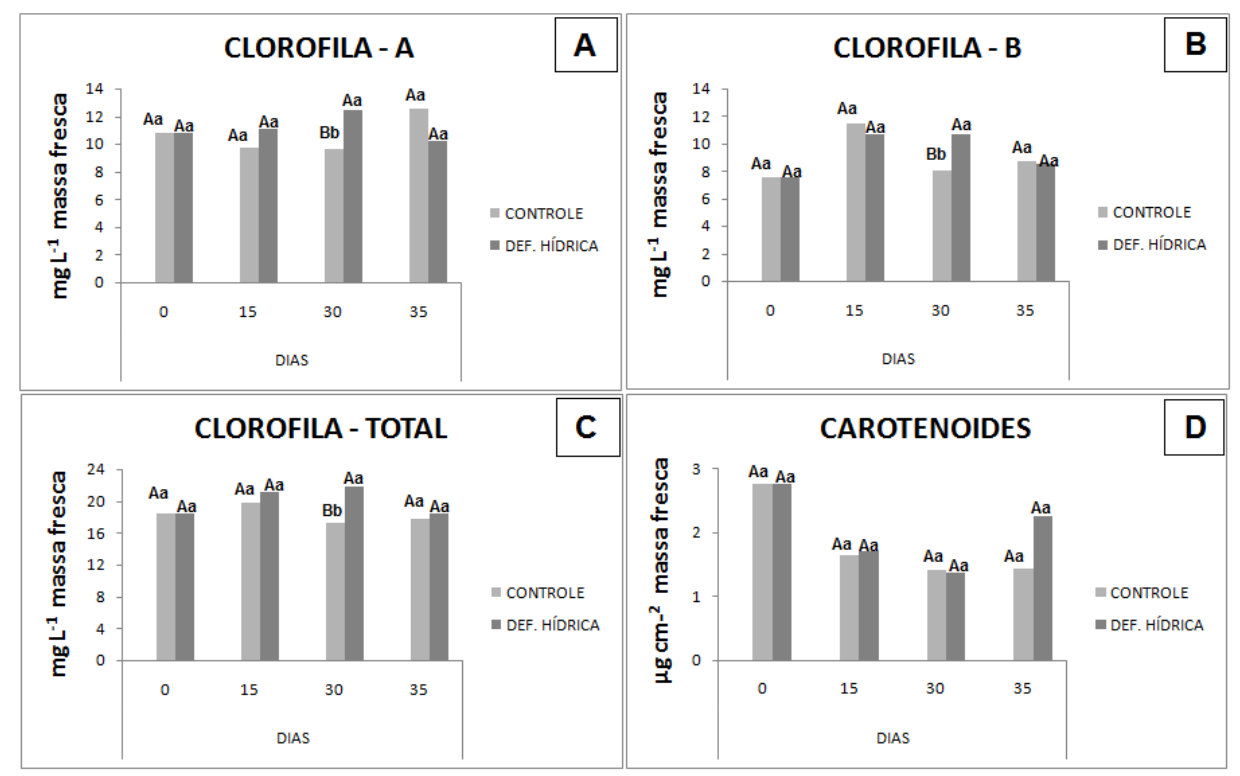

Figura 3. Teores de Clorofila $a$ (A), $b$ (B), totais (C) e Carotenóides (D) nas plantas de Oenocarpus mapora submetidos à deficiência hídrica e reihidratação.

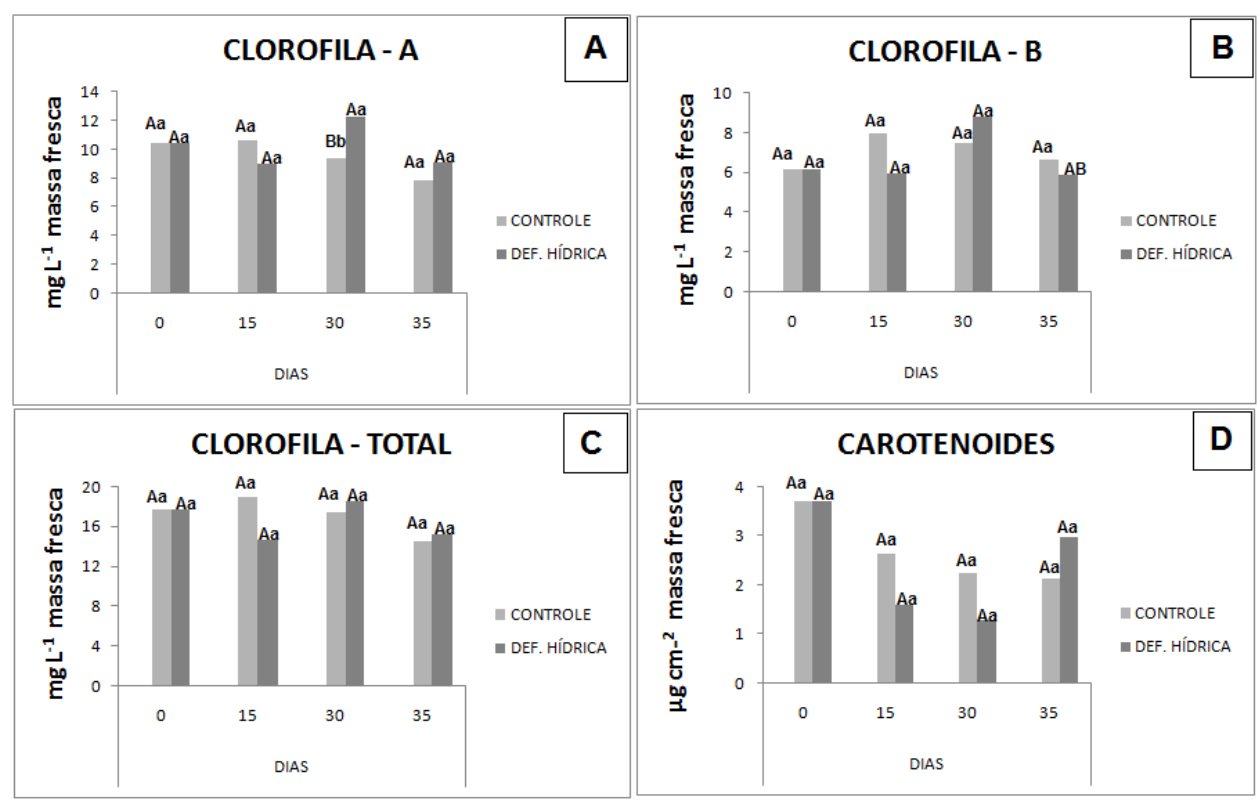




\section{Conclusões}

O tempo de restrição hídrica de 30 dias e de rei-dratação ao $35^{\circ}$ dia, foram suficientes para alterar o metabolismo bioquímicos das plantas de Oenocarpus bacaba e Oenocarpus mapora, através da redução do CRA, aumento da clorofila $a, b$ e totais e aumento dos teores de vazamento de eletrólitos e carotenóides.

\section{Referências}

ANGELOCCI, L. R. Água na planta e trocas gasosas/energéticas com a atmosfera: introdução ao tratamento biofísico. Piracicaba: Ed. do Autor, 2002. 272 p.

ENGEL, V.L.; POGGIANI, F. Estudo da concentração de clorofila nas folhas e seu espectro de absorção de luz em função do sombreamento em mudas de quatro espécies florestais nativas. Revista Brasileira de Fisiologia Vegetal, v.3, p.39- 45,1991.

FLEXAS, J.; BOTA, J.; LORETO, F.; CORNIC, G.; SHARKEY, T. D. Diffusive and metabolic limitations to photosynthesis under drought and salinity in $\mathrm{C} 3$ plants. Plant Biology, v. 6, p. 269279, 2004.

LEE, D.W. Simulating forest shade to study the development ecology of tropical plants: juvenile growth in three vines in India. Journal of Tropical Ecology, v.4, p.281-292, 1988.

LICHTENTHALER HK (1987). Chlorophylls and carotenoids: pigment photosynthetic biomembranes. Methods Enzymol. 148:362-385.

MENDONÇA, M.S. de M.; ARAÚJO, M.G.P. de. (1999). A semente de bacaba (Oenocarpus bacaba Mart- Arecaceae): aspectos morfológicos. Revista Brasileira de Sementes, vol. 21, no 1, p. 122-124.

MIRANDA, I. P. A.; RABELO, A. Guia de identificação das palmeiras de um fragmento florestal urbano. Manaus: Editora UFAM: INPA, 2006. 228 p.

MOLINARI, H.B.C.; MARUR, C. J.; DAROS, E.; CAMPOS, M. K. F. de; CARVALHO, J.R.F.P. de; BESPALHOK FILHO, J. C.; PEREIRA, L. F. P.; VIEIRA, L. G. E. Evaluation of the stressinducible prodution of proline in transgenic sugarcare (Saccharum spp.): osmotic adjustment, chlorophyll fluorescence and oxidative stresse. Physiologia Plantarum, v. 130, p 218-229, 2007.

REIS, F. O.; CAMPOSTRINI, E. Trocas gasosas e eficiência fotoquímica potencial em mamoeiro do grupo 'Formosa' cultivado em condição de campo. Bragantia, v.67, n.4, p. 815 - 822, 2008.

SLAVICK, B. Methods of studyng plant water relations. Springer Verlang, p. 449, 1979. 